\title{
From the editors of the issue
}

It is our pleasure to present a new and exciting issue of the Zeitschrift für Australienstudien. This year's contributions offer a wide range of disciplinary subjects, including Geography, Literary Studies, Translation Studies, Cultural Criticism and History. As editors of the journal, we try to foster the practice of Australian Studies as a multidisciplinary endeavour, thereby positioning the Zeitschrift für Australienstudien as a crucial forum for exchanging innovative scholarship.

We are also delighted to announce a change in the production of this journal from the University of Klagenfurt to the Wissenschaftlicher Verlag Trier, an academic publisher based in Trier, one of Germany's oldest cities. Under the new publisher, the journal's traditions of rigorous refereeing policies will continue, while allowing considerable room for substantial review articles and reviews to inform European and Australian readers about trends and innovations in publications relevant to Australian Studies. We regard the bilingual direction of the journal as one of its central strengths and unmistakable sign of plurality. We strongly encourage future submissions in both German and English language. Meanwhile, our Association continues to issue a bi-annual electronic Newsletter which presents news, reports and debates on Australia's current affairs. Australianists can visit the eNewsletter on www.australienstudien.org.

As part of our ongoing editorial innovations, we have great pleasure to welcome two distinguished academics as members of the journal's Advisory Board: the former editor of this journal, Adi Wimmer (University of Klagenfurt), and our first representative of Drama Studies, Maryrose Casey (Monash University, Melbourne). In close collaboration with the members of the Advisory Board we continue to position the Zeitschrift für Australienstudien as a central journal of Australian Studies in Europe. The production of this issue would not have been possible without the efforts of our authors, reviewers and anonymous referees. Many thanks indeed.

Henriette von Holleuffer \& Oliver Haag (November 2013) 